\title{
the Hospital
}

\section{as a Community Health Center}

EDWIN L. CROSBY, M.D., Dr.P.H.

Following is the Wilinsky Lecture, delivered at the Harvard School of Public Health, Boston, on October 14, 1957. The Charles F. Wilinsky Lecture Fund was established in 1954 to endow lectures on the role of the hospital in public health. Dr. Wilinsky served as executive director of Beth Israel Hospital in Boston and deputy health commissioner of that city. He is a former president of both the American Public Health Association and the American Hospital Association.

$\mathrm{T}$ HE HOSPITAL is a dynamic, not a static, institution. Looking at our hospitals in the context of American life and medical and scientific progress, we know that a revolution in hospital care is under way. In the words of Dr. James Mackintosh, emeritus professor of public health, School of Tropical Hygiene and Public Health, University of London, "It is exciting to live in a revolution; it is tragic not to realize it."

A little more than a half century ago it seemed that we'd gone about as far as we could. Then science exploded into medicine and almost overnight there was a whole galaxy of new treatment techniques, new equipment, and

Dr. Crosby is the director and a former president of the American Hospital Association. He served as director of Johns Hopkins Hospital, Baltimore, Md., from 1945 to 1952, and as director of the Joint Commission on Accreditation of Hospitals from 1952 to 1954. In 1950 he was the United States representative on the Expert Subcommittee on Hospital Statistics of the World Health Organization. new and different persomnel. Even professional workers in the health field must be astounded by the many new scientific developments which have changed hospital and health care in the last two generations. This period has been marked by the development of roentgenology; advances in the science of nutrition, including the discovery of vitamins; elimination of most of the infectious diseases through immunization, better control, and good public health practice; the control of diabetes with insulin; the discovery of the antibiotics; the medical use of radionuclides; new anesthetics making possible amazing surgical procedures; the use of human blood and its fractions; and so many other giant feats that I cannot possibly mention them all. During this period, medical thought broadened to see the individual as a physical and emotional whole. As Francis Peabody said, "What is spoken of as a clinical picture is not just a photograph of a man in bed; it is an impressionistic painting of the patient surrounded by his home, his work, his relations, his joys, sorrows, hopes and fears" (1).

In addition to the effect of new techniques in health care, hospitals have also felt the impact of dramatic social and economic developments in the United States. Our population is growing; we are now a nation of some 170 million, and by 1967 if the present rate of increase continues, we may well have a population of almost 200 million. There is a continuing increase in the proportions in our population of the elderly and of the very young, although we 
are often inclined to overlook the proportionate increase of the very young.

Through our fine educational system, through the various medical, hospital, and public health organizations, and through the work of public information media, this vast American public is growing in knowledge about health services and becoming increasingly appreciative of the value of health. Good health care has become part of the increasingly higher standard of living which more Americans can now afford. The improving economic conditions of the last two decades have been accompanied by new concepts of the responsibility of employers, unions, and government at all levels for maintaining health.

As a result of this growth in numbers and in understanding of health care, the utilization of hospitals has risen rapidly. From 1946 to 1956 the number of admissions to all hospitals increased 41 percent, and admissions to nonprofit, short-term hospitals, the community hospitals, increased 54 percent. This increased use of hospitals is not due solely to increased population. In 1946, there were 112 admissions per 1,000 population to all hospitals, and in $\mathbf{1 9 5 6}$ there were 132 admissions per 1,000 (2).

Meanwhile, the financial problems of hospitals have changed too. The costs of new buildings and of renovating old hospital facilities have been rising. Voluntary hospitals are no longer simply philanthropic institutions supported by private donations. Hospitals today are dependent on fees from patients or third parties such as Blue Cross, insurance companies, and public welfare agencies. Increased costs of operation have forced them to become business organizations. They are concerned with balaricing budgets and defining the full cost of services in order to collect from the patient, or in his behalf, the amounts necessary to sustain the hospital's operations.

Thanks to the growth of prepayment, the hospital as an economic organism is now more stable than ever before. But the public has yet to fully realize the dollar cost of health care. People want the best in health care. It must be paid for, in one way or another. Hospital and other workers in the health field must support the idea that people should set aside enough from their current income to enable them to pay for the best of care. We are responsible for seeing that they get a full dollar's worth of care for every dollar spent.

We in hospital careers feel the impact of revolutionary medical and social advances, and we are doing our best not only to adapt to them but also to advance hospital care as rapidly as possible.

\section{Hospitals and Public Health}

I would like to discuss one important aspect of hospital care, the hospital as a community health center. The community's investment in the hospital can best be realized when hospitals and public health authorities work together with the medical profession as partners in the teaching and practice of preventive medicine and public health. The relationship between the hospital and the public health profession has been, and continues to be, an important area for study, discussion, and action.

However, I would like to consider the hospital's contribution to the health of the public in a wider context; to describe some ways in which the hospital may serve its community; and finally, to discuss ways in which the public, through the hospital, may help improve the public health.

For many years, the hospital was virtually an island of curative medicine. To be sure, many hospitals thus insulated did a remarkably good job of serving their communities. But just as the practitioner of medicine can no longer limit his tools to his black bag, the average hospital today cannot offer the best care while limiting its resources to the skills found within its walls. If the hospital lives as an island in the community, concerned only with the patients who pass through its doors, not thinking whence they come or where they go, it is an incomplete public servant; it does not fully meet public demands.

I have heard Dr. Mackintosh say that while the function of hospitals today is "to care for the sick, in the future their function will be not to care for the sick, but rather the well." $\mathrm{He}$ emphasizes, and I agree with him, that its public health responsibility is one of the major functions of the hospital. In his words, "The good hospital acts as an intelligence service 
sending out, as necessary, danger warnings for the protection of the public. Its function is to watch the movement of sickness, to act early and with dispatch before great harm is done. ... Sickness is an incident in the life of an individual, but to the hospital and its staff, sickness is a challenge, a focus of enquiry from which prevention should radiate as well as cure." As early as 1936, the Committee on Public Health Relations of the American Hospital Association, of which Dr. Wilinsky was chairman, stated that newer conceptions of an adequate community health program emphasize "the gradual disappearance of the line of demarcation between the prevention and the treatment of disease" (3).

In fact, preventive medicine has long been a joint responsibility of the hospital and health departments. The hospital assists the work of the health department by deeds such as registering births and deaths; detecting and reporting communicable diseases; treating patients with tuberculosis and poliomyelitis; and continuing the never-ending fight against infection, a fight recently dramatized by the appearance of resistant strains of Staphylococcus aureus. The health department, especially in rural areas, may use the laboratory and other clinical facilities of the hospital. The hospital practices the principles of maternal, infant, and child hygiene, and tries to educate the patient and his family in these and other matters of health and hygiene."

The Ford Foundation reports that many hospitals used part of their foundation grant to improve educational facilities for the communities they serve; that they organized educational programs on such aspects of preventive medicine as maternal and child care, sex education, nutrition, mental hygiene, and early detection of serious diseases; and that their social service and outpatient departments "combine treatment with instruction in solving family health problems" (4). In the outpatient work of the hospital, cooperation between the health department and the hospital is closest. As the patient leaves the hospital, he is followed by the health department, which sees that the hospital's achievements are not lost and that he is restored to the greatest possible self-reliance.
Hospitals are also working out other new programs to extend their services to their communities. Individual hospitals and hospital associations are undertaking research in management aimed at expanding the hospital's responsibilities in community health protection. Subjects of such studies have included the planning of the hospital's physical plant, the improvement of food service, the possibility of organizing regional cooperation between large and small hospitals, and the development of new programs of outpatient and home care.

In another expansion of their service to their communities, hospitals are extending their emergency responsibilities beyond that of routine service in disaster planning: the resourceful organization of emergency equipment and procedures to save lives when natural or mechanical catastrophes engulf numbers of people. To be ready for communitywide emergency situations-whether fire, flood, tornado, or train or plane crash-hospitals are cooperating in planning with public health, civil defense, and other community agencies.

Another hospital activity, no longer new but of the utmost importance, is the voluntary program of hospital accreditation. Accreditation means that the quality of patient care in the hospital meets adequate standards. It is a stamp of approval conferred by the Joint Commission on Accreditation of Hospitals, an independent group formed in 1952. The public is becoming aware of the distinction between accredited and nonaccredited hospitals; the hospital which requests a survey and achieves accredited status, or is earnestly working toward that goal, vouches to the community that it is serving its best interests. Accreditation is a voluntary program of continued self-inspection, the strongest arm of freedom of medicine and hospitals. Through accreditation, hospitals indicate to their communities that with independence in a free society goes the responsibility to measure up to society's demands: National recognition that hospitals are striving to improve their services is indicated by the recent Ford Foundation grant to establish voluntary counseling service to help hospitals improve their administrative services and, as a result, their patient care. 


\section{Extending Services}

Four aspects of extending the hospitals' services into the community seem to me especially adventurous and important: planned cooperation between large and small hospitals, new rehabilitation programs, new types of care for the chronically ill, and new concepts of outpatient care.

We still need more precise definition of the elements of institutional care of the sick. Such definition would lead to more effective and economical care. The community hospital of the future will not stand alone, but must be linked in some organized way with other institutions. With such a link difficult problems can easily be referred to centers with more specialized facilities, and the staffs of outlying institutions can benefit regularly by visits from specialists from the more central and highly developed hospitals. Every community should have a carefully developed plan for orderly integration between health and welfare agencies and the various institutions offering health services.

I would make three suggestions to guide planning. First, the community plan must assure that each patient is treated in the type of institution that his condition requires. Second, we must organize professional disciplines and physical equipment to focus on special treatment problems, grouping patients according to need and where care can best be given. Third, patient transfer is a two-way street. We must move toward broader acceptance of transfer of patients from small hospitals to large medical centers as patient care dictates. And conversely, we must arrange for movement of patients from general hospitals to nursing homes, convalescent homes, or home care programs.

Rehabilitation, the second important aspect, is vital in the changing therapeutic picture. I have often thought that almost every patient who enters a hospital is in need of some kind of rehabilitation, whether a brief but encouraging chat, a mild form of special exercise, or, in more seriously disabled cases, intensive physiotherapy and psychotherapy. All members of the hospital staff will need to understand the importance of rehabilitation in the early stages of a patient's illness.
I believe that if we are to bring the benefits of rehabilitation services to communities-including the smaller ones-then the hope for establishing and developing such services rests with the community hospital. A centrally located rehabilitation center may be able to serve the patients of several hospitals in the area. These centers might have not only medical and directly allied facilities but also such services as vocational testing, guidance, and training.

Many hospitals now include rehabilitation among their services, but as Dr. Theodore Klumpp has pointed out, "The hospital is still only a repair shop where broken bodies are sent to be mended" (5). I would agree with him that some day it will also be a maintenance shop where the most intricate mechanism in the world will be sent to find out how it can best be cared for to prevent damage. The development of proper rehabilitation services in a community is one of the greatest challenges facing hospitals.

Problems relating to the illnesses that accompany middle and later life are a third growing concern in the health field. In fact, meeting the challenge offered by our increasing number of aging persons is probably the single greatest problem we face. George Bugbee, president of the Health Information Foundation, has reported that the group over 65 incurs 13.1 percent of all charges for health services although it constitutes only 8.4 percent of the population (6). And the problem will become greater. Today, more than 13 million people are 65 years of age or older, and by 1980, 1 out of every 7 people will be 65 or older, while 2 out of 5 will be 45 or older.

Because much of the illness that hospitals see will be chronic, hospitalization will generally be a relatively short episode in a long course of treatment, and care will have to be continued at home. In the future services provided at home cannot be limited, as they generally have been in the past, to those performed by doctors and nurses. The full range of services now provided only to the hospital inpatient must be properly adapted to home care.

New concepts of outpatient care open a fourth area of expanding hospital service. Along with the other revolutionary trends in hospital care will come the death of the old idea that ambulatory care is only for the poor. Very slowly, 
forced by a combination of economics, science, and good old-fashioned common sense, we are accepting the idea of ambulatory service to the whole community. Community hospitals take bed patients of all income groups, and in the future hospitals will probably eliminate financial distinctions among ambulatory patients as well. For both ambulatory and bed patients, it is becoming clearer that prepayment will be the means of paying hospital bills for the self-supporting, while tax funds assist the medically indigent and cover the cost for the indigent.

A major fault in our organizational plans for the care of ill persons has been that the plans seem to encourage patients to lie down in hospital beds in order to be eligible for prepayment benefits. Without the benefit of prepayment it is only natural for people to delay seeking the care they need. In the interest of good community health we must encourage prepayment plans to offer more complete coverage, adding to basic inpatient coverage on a service benefit basis both extended benefits and protection for the ambulatory patient.

\section{Need for Research}

In considering regional cooperation, outpatient care, and other new demands upon the hospital, I am repeatedly impressed with the problems of hospital administration and with the urgent need for hospitals to expand research into all phases of their operation. Hospital administration is being recognized as the demanding science and art that it is. With its singular system of relationships among the trustees, medical staff, administrator, other personnel, and volunteers, the hospital, of all institutions that I know, is the most difficult to administer. It is also one of the most satisfying. If the administrator is a skillful manager, he can help the complex health team work better together in the interest of the patients and their community. I predict that hospitals will become even more complex institutions to administer in the years to come. Two reasons for this prediction can be summed up in two words: costs and personnel.

The cost of hospital care has been rising, and there is no denying that it will continue to rise. A well-reasoned but admittedly conservative estimate made in 1954 was an increase at the rate of 5 percent per year $(7)$. From 1955 to 1956, the increase was 9 percent (2). Providing facilities and personnel for a widening range of services grows more expensive every year. The total expense of the Nation's short-term, nonprofit, general hospitals rose 223 percent from 1946 to 1956 . Better patient care today means both more skilled personnel to provide new technical services and simply more personnel of all types. In nonprofit, short-term hospitals, our community hospitals, personnel increased from 156 per 100 patients in 1946 to 213 per 100 patients in 1956 (2). No wonder payroll expense cuts the largest chunk from the hospital's budget, more than 60 percent of the total expense of nonprofit, short-term, general hospitals in 1956.

At the same time that the number of personnel has been increasing, the number of hours in the workweek of hospital personnel, like those in offices and factories, has been decreasing. The difference is that the hospital must operate 24 hours a day; 168 hours a week, 52 weeks a year, always ready for any emergency. The shorter workweek has frequently been helpful in attracting additional qualified personnel, but because of the around-the-clock nature of the hospital's activities, it has also necessitated many more workers, a larger payroll, higher costs, and inevitably higher charges.

As hospitals convert the results of medical research into ever more comprehensive patient care, they may reasonably expect that the percentage of the hospital budget allotted to payroll will rise to more than 70 percent. As wages rise generally, they must rise in hospitals. Hospital administrators in virtually every community face an acute and seemingly chronic shortage of personnel. Hospital careers offer well-recognized satisfactions of service, association with the aura of medical learning, and the prestige of the uniform of healing. But recruitment will not be easier until hospitals can compete with other employers' wages. Hospitals must make sure that they use their staff wisely and do not waste talent and training.

Automation can never be the complete answer for personal service institutions; reducing costs by increasing productivity is far more difficult in hospitals than in industry. 
Yet I am optimistic enough to think that studies will show us how automation can be exploited more fully, for example, in food service, laundry, central supply, and other such departments. Through improved methods and work simplification, hospitals will undoubtedly be able to increase the efficient use of workers' time. We must stop viewing with alarm the rising costs of hospital care, but we must not cease our efforts to keep costs down to the minimum consistent with maximum quality. Hospitals must demonstrate to the public that they recognize the need for economical operation in line with sound business procedures.

Solutions to the problems created by rising costs and shortages of personnel as well as the radical changes in the patterns of patient care will be worked out through research by hospitals' administrative staffs, by all members of the health team, and by social scientists. We often think of research in terms of new drugs, new surgical techniques, and other giant steps in the march of medicine. There is other research that is conducted with as much sincerity of purpose and with results as directly related to patient care. After all, it is the hospital with its laboratories, clinics, and operating facilities that makes it possible for the physician to practice modern medicine.

Until lately research in hospital administration was sparse. We have finally been able to get underway, through foundation and HillBurton funds, the organized program of hospital research which we have desired for so long. The American Hospital Association has strenuously urged increased recognition of the importance of research. It was instrumental in setting up two important national research groups. One, the Commission on Hospital Care, offered the first analysis of the extent to which the Nation's health resources were meeting the increased demand for health services (8). The commission's report prescribed a much-needed pattern for orderly planning of health facilities, a pattern which influenced the development of the very successful Hill-Burton program.

The second, the Commission on Financing of Hospital Care, did the first comprehensive analysis of the basic problems in financing hospital care for the American people (9). The
American Hospital Association also participated in the Commission on Chronic Illness, which has completed a 7-year study of the problems of chronic disease, illness, and disability (10).

The Association led in the establishment of the Hospital Research and Educational Trust, a nonprofit, citizen-directed body to undertake needed research in hospital affairs. The trust has, from several sources, about $\$ 4.3$ million programed in current research or pledged for future research. It is conducting studies of medical records, hospital licensure, need for future hospital facilities, and construction and design.

I would certainly predict that in the years to come hospitals of all sizes and types will become more active in conducting research. For too long we have thought research could be undertaken only in large medical centers. Actually, all hospitals can keep the accurate records which offer a basis for investigations to determine such things as the relation of social factors to disease and a community's actual and potential needs for various health services. All hospitals can undertake studies designed to evaluate and improve their administration. If we stop labeling these activities with the bogeyword "research," perhaps we can encourage acceptance of the fact that they can be undertaken outside university citadels of learning.

You may have noticed that in speaking of these research programs and the extension of hospital services to which they lead-in describing to you the ways in which today's hospital is living up to its responsibilities as a community health center-my point of view has been rather one-sided; I have been dwelling on the functions of the community it serves.

Adequate preventive as well as curative health care has become an accepted part of the high standard of living which most Americans are now able to attain. The potential consumers of medical care have a right to help plan for community health, and they are becoming more vocal in their desire to do so. I believe that health care can be no better than the people demand. I believe that the people should be as concerned as professional health personnel with the form and the cost of medical care, and the method of paying for it. In the 
United States we are fortunate that we have an interested and aroused public, which, if it does not understand all the technical details of our work, understands a great deal more than we frequently give it credit for, and recognizes the importance of health care.

Our community hospitals are built by voluntary contributions from private citizens. Some 115 million Americans are identified with hospitals even before they set foot in one, either through Blue Cross or one of the many commercial insurance plans. The hospital cannot refuse to respond to the demands which the public need places on it. The community in turn must support its hospital. Support it with money, yes, and with a supply of personnel; but above all with a vivid understanding of the hospital's purpose and encouragement of the professional hospital team.

\section{Lay Leadership}

In trying to assess the hospital in the rapidly changing community health picture, I find one constant of great importance, a constant unique to the United States. Our community hospitals are truly governed, not by a professionally trained group, but by laymen, community leaders, who are better known for other personal achievements, but who have demonstrated an abiding interest in the community's welfare. Of course, our hospitals are not unique in this regard. Professional educators do not generally govern universities; military men do not establish final policy in the Department of Defense; and nuclear physicists do not speak the last word in the Atomic Energy Commission's decisions on the uses of atomic energy-or space satellites. Major institutions other than hospitals are governed by boards of so-called "lay" trustees. Yet the most highly developed forms of contributed service in our society are those centered in our hospitals, with their trustees, their volunteers, and their members of the religious orders. The story of the founding of every voluntary hospital in America always has a basic theme, contributed service.

The hospital trustees of the Nation-some 50,000 of them - are entrusted with the responsibility of setting policy in medical institutions where only the most expertly trained physicians and paramedical workers can translate the latest in scientific developments into the best of patient care. The point to remember is the desirability of this arrangement. The lay control of hospitals insures that the community's interest will never be overlooked.

Of course, hospital trustees and volunteers must be particularly sensitive to the hospital's purpose and needs. Theirs must be educated awareness, including a recognition of the need for good equipment and well-trained personnel, an understanding of the problems of the physician and his co-workers, and an effort to facilitate their dedicated labors. As professional health workers, we all have an obligation to educate our communities about the goals and means of health care.

The modern hospital has evolved, not step by orderly step, but by a series of rapid mutations which have not yet stopped. Advances in medicine and changing social and economic conditions are making new demands on the hospital. Its functions of caring for patients, educating future health workers, and serving as a medical research center reach outside its walls into the community. The American public is learning to demand more extensive health services. If the hospital is to maintain its place in the public esteem, it must be prepared to adapt to this demand.

Voluntary hospitals demonstrate how consumers of health services can be effective partners with the producers of these services. Such partnerships have obvious advantages and are bulwarks of strength to our free society. The degree to which the relationship succeeds in a hospital is a major factor in determining the quality of patient care, preventive medicine, and educational and research activities.

I believe that our voluntary hospital system, directed by lay leadership representative of the community, will continue to serve the people to the extent that the public desires service. In the voluntary hospital, the full partnership of an enlightened public, a learned and inspired medical profession, and a dedicated hospitaí administration represents an opportunity to offer the very best in health care. The American hospital was created out of the pattern of American democracy. It serves in a great tradition, and in the years ahead it will assume an even greater place as a community health center. 
As an institution, it has done much and yet has much to do. It needn't be apologetic. It cannot be complacent. Its accomplishments and its challenges are succinctly stated in the Passavant motto: "More than yesterday. Less than tomorrow."

\section{REFERENCES}

(1) Peabody, F.: Care of the patient. Cambridge, Mass., Harvard University Press, 1927, p. 15.

(2) Hospital statistics discussion. Hospitals (Guide Issue) 31: 348, 350, Aug. 1, 1957, Part II.

(3) American Hospital Association: Transactions. Chicago, 1936, p. 104.

(4) The Ford Foundation: The difference it makes. New York, N. Y., 1957.
(5) Klumpp, T. G.: Hospitals in the changing climate of medical care. Trustee $9: 1-4$, October 1956.

(6) Bugbee, G.: Population change and health care. Hospitals 30 : 32-35, 100, May 1, 1956.

(7) Brown, R. E.: The nature of hospital costs. Hospitals 30 : 36-40, Apr. 1, 1956.

(8) Commission on Hospital Care: Hospital care in the United States. New York, N. Y., Commonwealth Fund, 1947.

(9) Commission on Financing of Hospital Care : Financing hospital care in the United States. New York, N. Y., Blakiston Co., 1954-55, vols. 1-3.

(10) Commission on Chronic Illness: Chronic illness in the United States. Cambridge, Mass., Harvard University Press, 1956, vols. 1-4.

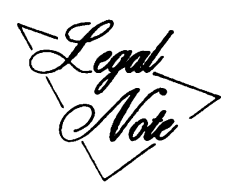

\section{Water Pollution Control}

Continued pollution of stream by municipality's sewage system after decree enjoining pollution constitutes civil contempt of court by municipality and criminal contempt by individual officials failing to take necessary steps to abate pollution, In re Borough of West Wildwood et al., 4.2 N. J. Super. 282, 126 A. 2 d 233 (1956).

The Borough of West Wildwood was directed by a chancery court in 1934 to comply with an order of the New Jersey State Department of Health to desist and refrain from allowing its improperly treated sewage to flow into Post Creek or to correct the inadequacy by a specific date. Four times over a period of 20 years the borough was found guilty of contempt of this order. The first contempt was punished by a fine of $\$ 50$ against each city councilman and $\$ 250$ against the borough.

The second finding of contempt was followed by the borough agreeing to make the necessary corrections in the sewage treatment plant. After the third finding of contempt, the borough was directed to raise the necessary monies to complete the correction of the sewage treatment plant.

Upon the failure of the borough to comply with this direction, the court in January 1955 levied a fine of $\$ 5000$ against the borough, in addition to a fine of $\$ 25$ per day until it com- plied with the order and $\$ 500$ against each councilman-defendant who voted "no" or refrained from voting on the borough ordinance providing for correction and installation of new sanitary sewage disposal facilities and authorizing issuance of bonds to help finance such construction.

On application for remission of fines the court remitted the fine levied against the borough upon condition that it be used for the amortization of some portion of its bonded indebtedness. The fines levied against the mayor and councilmen, which were imposed for criminal contempt, were held to be beyond the power of the court to remit after the expiration of 60 days from the date of judgment.

For cases involving a similar situation see Department of Health of State of New Jersey v. Borough of Fort Lee, 108 N. J. Eq. 139, 154 A. 319 (1931), and In re Borough of Fort Lee, 108 N. J. Eq. 425, 155 A. 473 (1931). 